\title{
Experiences of intimate partner violence as perpetrated among Japanese university freshmen
}

\author{
Haruka Shozaki-Ito ${ }^{1}$, Tomoko Shibayama ${ }^{2}$, Yumi Matsuyama ${ }^{3}$, and Mayumi Ohnishi ${ }^{2}$ \\ ${ }^{I}$ Yokohama City Minato Red Cross Hospital, Yokohama, Japan \\ ${ }^{2}$ Nagasaki University Graduate School of Biomedical Sciences, Nagasaki, Japan \\ ${ }^{3}$ Nagasaki University Hospital, Nagasaki, Japan
}

\begin{abstract}
Objectives: To compare experiences regarding the perpetration of intimate partner violence among Japanese university freshmen between 2008 and 2014.

Study design: Two-stage cross-sectional study.

Methods: A self-administered questionnaire survey was completed in both 2008 and 2014 by students at the same university.

Results: There were significant reductions in episodes of verbal harassment (adjusted odds ratio [AOR]: 0.601, 95\% confidence interval $[\mathrm{CI}]: 0.382,0.945, P=0.027$ ) that occurred when a boy/ girlfriend said "you don't give me priority" to his/her partner when they did not see them (AOR: 0.450, 95\%CI: 0.207, 0.979, $P=0.044$ ), and also in instances of irritation that resulted when a boy/girlfriend disobeyed his/her partner (AOR: 0.385, 95\%CI: $0.161,0.921, P=0.032$ ) from 2008 to 2014 . The perpetration scores were reduced from $1.87 \pm 0.16$ in 2008 to $1.41 \pm 0.117$ in 2014 ( $t$ test, $P=0.016)$. The perpetration scores in 2014 were significantly lower than those in 2008, regardless of gender, age, university faculty, and participation in lectures/seminars about domestic violence (DV) and/or dating DV $(P=0.030)$.

Conclusions: Findings showed reductions in some types of harassment, as well as in perpetration scores, between 2008 and 2014 among Japanese university freshmen at the same university. However, further study is required to determine the factors related to the perpetration of harassment.
\end{abstract}

Key words: intimate partner violence, perpetrator, Japanese university student

(J Rural Med 2018; 13(1): 33-39)

Received: September 4, 2017

Accepted: January 9, 2018

Correspondence: Mayumi Ohnishi, M.P.H. Ph.D., Nagasaki University Graduate School of Biomedical Sciences, 1-7-1 Sakamoto, Nagasakishi, Nagasaki 852-8520, Japan

E-mail: mohnishi@nagasaki-u.ac.jp

This is an open-access article distributed under the terms of the Creative Commons Attribution Non-Commercial No Derivatives (by-nc-nd) License $<$ http://creativecommons.org/licenses/by-nc-nd/4.0/>.

\section{Introduction}

Intimate partner violence (IPV) is a serious worldwide health problem ${ }^{1,2)}$. Although the prevalence of IPV as reported by Japanese women is low in comparison to other countries that were included in a previous multinational study performed by the World Health Organization (WHO) $)^{1,3)}, 19.1 \%$ of female respondents and $10.6 \%$ of male respondents in a 2014 study conducted by the Gender Equality Bureau Cabinet Office in Japan reported that they had experienced some type of violence, including physical, psychological, economic, and/or sexual violence ${ }^{4}$. In addition, the prevalence rates increased from $13.7 \%$ of females and $5.8 \%$ of males in a follow-up study conducted in $2011^{5}$. A previous study indicated that most Japanese university students did not recognize verbal harassment, control by an intimate partner, or unprotected sexual intercourse as forms of violence ${ }^{\text {). }}$. Thus, these students may not consider the seriousness of the impact of violence in the present or future, although several studies have shown that violence has a negative impact on health over long periods ${ }^{2,7-9)}$.

The Third Gender Equality Participation Basic Plan ratified by the Cabinet Office in 2010 emphasized education as a means of preventing violence beginning in the early stages of childhood and adolescence in Japan. In the Nagasaki prefecture where the 2008 study regarding IPV among university students was conducted ${ }^{8}$, the sale and gifting of contraceptive supplies to people under 18 years of age were controlled as part of the Prefectural Juvenile Protection Regulations, which were enacted in 1978. However, these regulations were abolished in 2011. In 2001, The Domestic Violence Prevention Act was established in Japan. The act covered partner violence that occurred in legal marriages, but did not recognize IPV, although it did address post-divorce partner violence. The act was amended in 2013 to cover violence that occurred between unconventionally 
married couples, such as those in common law marriages, but still does not cover IPV. This includes dating violence that occurs between couples that are not engaged in communal life similar to that in marital relations.

A number of reports have included IPV as a serious health challenge for adolescents and youth ${ }^{10)}$. In addition, the onset of dating violence perpetration has been shown to occur during the teenage years ${ }^{11)}$. Unfortunately, limited evidence is available regarding approaches and programs that are effective in IPV prevention, including the complex factors that influence both perpetration and victimization ${ }^{12}$. In addition, if there is a possibility that the incidence rate of IPV has been underestimated and underreported in Japan ${ }^{1,3,8)}$, a periodic assessment of the actual situation regarding IPV in Japan, especially among young people, will be important for identifying measures for prevention and preparedness.

This study was performed to compare experiences of IPV perpetration among Japanese university freshmen of the same university between 2008 and 2014'). There were several changes in the laws and regulations regarding sexual health and violence prevention between 2008 and 2014 in both Japan and this study area. However, the changes did not sufficiently correspond to concerns related to violence prevention and the future impact of violence on health conditions. This study was performed to assess differences in the attitudes and behaviors of university students as related to the prevention of IPV, and was designed to especially address experiences of perpetration.

\section{Methods}

This was a two-stage cross-sectional study. A self-administered questionnaire survey was performed in 2014 among freshmen from both medical and non-medical health faculties at a university in the capital city of a Japanese prefecture. The same questionnaire was conducted at this university in 20086). Some participants attended a lecture related to DV and IPV as part of liberal studies education for students of all faculties at the university, and/or similar lectures outside the university. Some lectures were attended prior to entering the university. After receiving oral and written explanations regarding the study objectives, procedures, management of data collection, confidentiality, and ethical considerations about participation or refusal to participate in this study, the participants provided informed consent prior to completing the questionnaire. The completed questionnaires were then deposited in a locked opaque box. Data collection was performed in the first academic year of both study years.

The questionnaire elicited responses regarding demographic characteristics, being the victim/perpetrator of ha- rassment from and/or toward a boy/girlfriend, and the recognition of harassment as dating violence. If a participant recognized an episode listed in the questionnaire as relating to their own experience of harassment toward and/or from their boy/girlfriend, they answered "yes". These episodes were developed based on a booklet titled "Do you know about dating violence?" that was published by the non-profit organization DV Prevention Nagasaki, and which included physical, psychological, verbal, sexual, and economic forms of harassment. The study methods, including the questionnaire, were previously described in detail ${ }^{6}$.

This study was conducted between 2008 and 2014, and focused on situations in which dating violence was perpetrated by using 24 episodes of harassment. Either Fisher's exact test or the chi-square test was used to analyze differences in the demographic information of study participants, as well as their experiences of violence perpetration while dating a partner between 2008 and 2014. A logistic regression analysis was performed to assess differences in experiences of violence while dating a partner, regardless of gender, age, or university faculty. The perpetration score was calculated for each participant by totaling the number of "yes" responses to prompts describing 24 episodes of violence. Scores from 2008 and 2014 were then compared using the $t$ test and a linear regression analysis. Statistical analyses were performed using IBM SPSS ver. 22. In all analyses, $P<0.05$ was taken to indicate statistical significance.

\section{Ethical approval}

The 2014 study was approved by the Ethical Committees of Nagasaki University Graduate School of Biomedical Sciences (authorization number: 13102461). The same committees also approved utilization of the data collected in 2008 (authorization number: 14031389).

\section{Results}

A total of 274 responses from the 2008 data collection and 371 responses from the 2014 data collection were analyzed. This included data regarding gender, age, university faculty, whether participants had relationships with boy/ girlfriends, and whether they had participated in lectures/ seminars about domestic violence (DV) and/or dating violence. The study participants in 2008 and 2014 represented $16.7 \%$ and $22.4 \%$ of the university's freshmen, respectively. Responses regarding demographic information and relationships with the opposite gender are shown in a statistical analysis in Table 1, which also provides a comparison of all study participants with those that had a boy/girlfriend. The 2014 study participants were predominantly male (chi-square test, $P<0.001$ ) and younger (chi-square test, 
Table 1 Demographic information and relationships with the opposite gender

\begin{tabular}{|c|c|c|c|c|c|c|c|c|c|c|}
\hline & \multicolumn{5}{|c|}{ All study participants $(n=645)$} & \multicolumn{5}{|c|}{ Study participants with a boy/girlfriend $(n=403)$} \\
\hline & \multicolumn{2}{|c|}{$\begin{array}{l}\text { Year } 2008 \\
(n=274)\end{array}$} & \multicolumn{2}{|c|}{$\begin{array}{l}\text { Year } 2014 \\
(n=371)\end{array}$} & \multirow[t]{2}{*}{$P$} & \multicolumn{2}{|c|}{$\begin{array}{l}\text { Year } 2008 \\
(n=174)\end{array}$} & \multicolumn{2}{|c|}{$\begin{array}{l}\text { Year } 2014 \\
(n=229)\end{array}$} & \multirow[t]{2}{*}{$P$} \\
\hline & $n$ & $\%$ & $n$ & $\%$ & & $n$ & $\%$ & $n$ & $\%$ & \\
\hline \multicolumn{11}{|l|}{ Gender } \\
\hline Male & 126 & 46.0 & 246 & 66.3 & $<0.001$ & 80 & 46.1 & 148 & 64.6 & $<0.001$ \\
\hline Female & 148 & 54.0 & 125 & 33.7 & & 94 & 54.0 & 81 & 35.4 & \\
\hline \multicolumn{11}{|l|}{ Age } \\
\hline 18 years old & 105 & 38.3 & 236 & 63.6 & $<0.001$ & 64 & 36.8 & 154 & 67.2 & $<0.001$ \\
\hline 19 years old & 124 & 45.3 & 104 & 28.0 & & 83 & 47.7 & 56 & 24.5 & \\
\hline 20 years old & 45 & 16.4 & 31 & 8.4 & & 27 & 15.5 & 19 & 8.3 & \\
\hline \multicolumn{11}{|l|}{ Faculty } \\
\hline Non-medical health faculty & 153 & 55.8 & 255 & 68.7 & $<0.001$ & 94 & 54.0 & 158 & 69.0 & 0.002 \\
\hline Medical health faculty & 121 & 44.2 & 116 & 31.3 & & 80 & 46.0 & 71 & 31.0 & \\
\hline \multicolumn{11}{|c|}{ Had a relationship with a boy/girlfriend } \\
\hline No & 100 & 36.5 & 142 & 38.3 & 0.645 & & & & & \\
\hline Yes & 174 & 63.5 & 229 & 61.7 & & & & & & \\
\hline \multicolumn{11}{|c|}{ Participated in lectures/seminars about DV and/or dating DV } \\
\hline No & 110 & 40.1 & 84 & 22.6 & $<0.001$ & 61 & 35.1 & 53 & 23.1 & 0.009 \\
\hline Yes & 164 & 59.9 & 287 & 77.4 & & 113 & 64.9 & 176 & 76.9 & \\
\hline
\end{tabular}

Chi-square test.

$P<0.001$, with most belonging to non-medical health faculties (chi-square test, $P=0.001$ ). These participants were more likely to have participated in lectures/seminars about DV and/or dating violence. However, there was no significant difference in the proportion of participants that had experienced a relationship with a boy/girlfriend between 2008 and 2014.

Table 2 compares experiences of 24 harassment perpetration episodes between 2008 and 2014 study participants using either the chi-square test or Fisher's exact test, along with a logistic regression analysis adjusting for gender, age, and university faculty. Cronbach's alpha for the 24 episodes had values of 0.719 and 0.658 in 2008 and 2014, respectively. The most common types of harassment in both study years were verbal harassment, checking and controlling boy/ girlfriend's activities, and ignoring a boy/girlfriend. Several episodes were significantly reduced between 2008 and 2014 for both bivariate and logistic regression analyses (i.e., verbal harassment (adjusted odds ratio [AOR]: 0.601, 95\% confidence interval [CI]: $0.382,0.945, P=0.027)$, saying "you don't give me priority" when boy/girlfriend does not see her/him (AOR: 0.450, 95\%CI: 0.207, 0.979, $P=0.044$ ), and irritation when boy/girlfriend disobeys her/him (AOR: $0.385,95 \%$ CI: $0.161,0.921, P=0.032)$ ). "Blaming the boy/ girlfriend if she/he gets angry because he/she is at fault" was also significantly reduced between 2008 and 2014 in the bivariate analysis (chi-square test, $P=0.021$ ), but this dif- ference was not detected in the logistic regression analysis.

The means \pm standard deviation (SD) of perpetration scores were $1.87 \pm 0.16$ and $1.41 \pm 0.12$ in 2008 and 2014, respectively ( $t$ test, $P=0.016$ ). Regardless of gender, age, university faculty, and participation in lectures/seminars about DV and/or dating DV, the perpetration score in 2014 was significantly low $(P=0.030)$ according to model A on the linear regression analysis (Table 3 ). Participation in lectures/seminars about DV and/or dating DV showed no contribution to the perpetration score because model B without participation in lectures/seminars about DV and/or dating DV as independent variables still showed a significantly low perpetration score in $2014(P=0.025)$.

Only two episodes (i.e., verbal harassment (AOR: 1.595, 95\%CI: 1.039, 2.451, $P=0.033)$ and ignoring boy/girlfriend (AOR: 1.743, 95\%CI: 1.086, 2.797, $P=0.021)$ ) were more common among female than male participants, regardless of study year and age. There were no significant differences in other episodes between male and female participants, nor were there any significant differences between non-medical health and medical health faculty members, regardless of study year and gender. There was also no significant difference in perpetration scores between male and female study participants $(1.61 \pm 2.10$ and $1.60 \pm 1.63$, respectively; $t$ test, $P<0.960)$. The perpetration score among male study participants was significantly different between 2008 and 2014 $(2.01 \pm 2.41$ and $1.39 \pm 1.88$, respectively; $t$ test, $P<0.033)$, 
Table 2 Experiences of harassment toward a partner among university students that have had a relationship with a boy/girlfriend by study year $(n=403)$

\begin{tabular}{|c|c|c|c|c|c|c|c|c|}
\hline & \multicolumn{2}{|c|}{$\begin{array}{l}\text { Year } 2008 \\
(n=174)\end{array}$} & \multicolumn{2}{|c|}{$\begin{array}{l}\text { Year } 2014 \\
(n=229)\end{array}$} & \multirow[t]{2}{*}{$P^{\text {a }}$} & \multicolumn{2}{|c|}{$\begin{array}{l}\text { Experience: Year } 2014 \\
\quad \text { (ref: year 2008) }\end{array}$} & \multirow[t]{2}{*}{$P^{\mathrm{b}}$} \\
\hline & $n$ & $\%$ & $n$ & $\%$ & & AOR & $95 \% \mathrm{CI}$ & \\
\hline I have called my boy/girlfriend "ugly" or "a fool". & 68 & 39.1 & 64 & 27.9 & 0.018 & 0.601 & $0.382,0.945$ & 0.027 \\
\hline $\begin{array}{l}\text { I have asked my boy/girlfriend "What is more important, me or } \\
\text { another/others." }\end{array}$ & 13 & 7.5 & 5 & 2.2 & 0.011 & 0.277 & $0.092,0.836$ & 0.023 \\
\hline $\begin{array}{l}\text { If my boy/girlfriend does not see me, I have said "You don't give } \\
\text { me priority." }\end{array}$ & 21 & 12.1 & 12 & 5.2 & 0.013 & 0.438 & $0.199,0.961$ & 0.040 \\
\hline I have checked where my boy/girlfriend is and who he/she sees. & 33 & 19.0 & 55 & 24.0 & 0.224 & 1.350 & $0.804,2.265$ & 0.257 \\
\hline $\begin{array}{l}\text { I have become angry because I wanted to know with whom my boy/ } \\
\text { girlfriend was talking. }\end{array}$ & 41 & 23.6 & 48 & 21.0 & 0.533 & 0.857 & $0.517,1.423$ & 0.552 \\
\hline I have meddled with my boy/girlfriend's relationships with friends. & 12 & 6.9 & 17 & 7.4 & 0.839 & 0.918 & $0.402,2.098$ & 0.839 \\
\hline $\begin{array}{l}\text { I have checked my boy/girlfriend's cell phone records without per- } \\
\text { mission from my boy/girlfriend. }\end{array}$ & 6 & 3.4 & 5 & 2.2 & 0.440 & 0.764 & $0.212,2.755$ & 0.681 \\
\hline $\begin{array}{l}\text { I have demanded my boy/girlfriend delete someone's contact infor- } \\
\text { mation from his/her cell phone. }\end{array}$ & 6 & 3.4 & 7 & 3.1 & 0.826 & 0.627 & $0.193,2.036$ & 0.437 \\
\hline $\begin{array}{l}\text { I have deleted someone's contact information from his/her cell } \\
\text { phone. }\end{array}$ & 1 & 0.6 & 0 & 0.0 & 0.432 & - & & \\
\hline I have become irritated if my boy/girlfriend disobeys me. & 18 & 10.3 & 9 & 3.9 & 0.011 & 0.385 & $0.161,0.921$ & 0.032 \\
\hline $\begin{array}{l}\text { I have directed to my boy/girlfriend where to go and what activities } \\
\text { they are allowed to do. }\end{array}$ & 18 & 10.3 & 14 & 6.1 & 0.120 & 0.564 & $0.257,1.234$ & 0.152 \\
\hline $\begin{array}{l}\text { I have blamed my boy/girlfriend if I get angry, because he/she is at } \\
\text { fault. }\end{array}$ & 19 & 10.9 & 11 & 4.8 & 0.021 & 0.517 & $0.229,1.171$ & 0.114 \\
\hline I have kissed or touched my boy/girlfriend against their wishes. & 5 & 2.9 & 3 & 1.3 & 0.299 & 0.246 & $0.054,1.129$ & 0.071 \\
\hline $\begin{array}{l}\text { I have had sexual relations with my boy/girlfriend against their } \\
\text { wishes. }\end{array}$ & 3 & 1.7 & 1 & 0.4 & 0.320 & 0.150 & $0.014,1.615$ & 0.118 \\
\hline $\begin{array}{l}\text { I have taken money or credit cards from my boy/girlfriend's wallet/ } \\
\text { purse. }\end{array}$ & 0 & 0.0 & 0 & 0.0 & & - & & \\
\hline $\begin{array}{l}\text { I have tried to injure myself in front of my boy/girlfriend when } \\
\text { unhappy. }\end{array}$ & 3 & 1.7 & 2 & 0.9 & 0.656 & 0.352 & $0.054,2.301$ & 0.276 \\
\hline I have injured myself in front of my boy/girlfriend when unhappy. & 1 & 0.6 & 2 & 0.9 & 1.000 & 1.466 & $0.120,17.881$ & 0.765 \\
\hline I have broken or taken away items precious to my boy/girlfriend. & 0 & 0.0 & 0 & 0.0 & & - & & \\
\hline I have ignored my boy/girlfriend. & 41 & 23.6 & 54 & 23.6 & 0.997 & 1.161 & $0.704,1.913$ & 0.559 \\
\hline I have beaten or kicked my boy/girlfriend. & 3 & 1.7 & 3 & 1.3 & 1.000 & 0.818 & $0.145,4.606$ & 0.820 \\
\hline $\begin{array}{l}\text { I have hit something or shouted in front of my boy/girlfriend when } \\
\text { angry. }\end{array}$ & 3 & 1.7 & 2 & 0.9 & 0.656 & 0.540 & $0.080,3.653$ & 0.528 \\
\hline I have pressed my boy/girlfriend for money. & 0 & 0.0 & 2 & 0.9 & 0.508 & - & & \\
\hline I have not returned money borrowed from my boy/girlfriend. & 4 & 2.3 & 2 & 0.9 & 0.409 & 0.324 & $0.053,1.972$ & 0.222 \\
\hline $\begin{array}{l}\text { I have demanded that my boy/girlfriend not attend a meeting/party } \\
\text { that I was not also attending. . }\end{array}$ & 6 & 3.4 & 4 & 1.7 & 0.340 & 0.263 & $0.067,1.031$ & 0.055 \\
\hline
\end{tabular}

Numbers and percentages indicate the study participants that responded "yes" to each question. ${ }^{a}:$ Chi-square test or Fisher's exact test. ${ }^{\text {b }}$ Logistic regression analysis was conducted adjusting for gender, age, and faculty.

although no such difference was observed among female study participants $(1.74 \pm 1.69$ and $1.43 \pm 1.55$, respectively; $t$ test, $P<0.207)$.

Tables 2 and 3 show the results of statistical analyses among study participants that had relationships with boy/ girlfriends. Eight (8.0\%) of the 100 participants in 2008 and 19 (13.4\%) of the 142 participants in 2014 that had experienced a relationship with a boy/girlfriend reported having perpetrated some type of IPV. The most common incidents were verbal harassment, checking and controlling a boy/ 
Table 3 Factors associated with perpetration score toward boy/girlfriend among study participants with a boy/girlfriend $(n=403)$

\begin{tabular}{lrrrrr}
\hline & \multicolumn{2}{c}{ Model A } & & \multicolumn{2}{c}{ Model B } \\
\cline { 2 - 3 } \cline { 5 - 6 } & $\beta$ & $P$ & & $\beta$ & $P$ \\
\hline Study year (2008/2014) & -0.116 & 0.030 & & -0.118 & 0.025 \\
Gender (Male/Female) & -0.009 & 0.872 & & -0.011 & 0.836 \\
Age & 0.040 & 0.448 & & 0.040 & 0.446 \\
Faculty (non-medical health/medical health) & -0.045 & 0.408 & & -0.046 & 0.402 \\
Participation in lectures/seminars about DV and/or dating DV (No/Yes) & -0.018 & 0.726 & & \\
\hline
\end{tabular}

Linear regression analysis.

girlfriend's activities, and ignoring a boy/girlfriend. However, one participant reported beating or kicking their partner, and another reported hitting something or shouting in front their partner.

\section{Discussion}

Results of the present study indicated reductions in some types of harassment and IPV perpetration scores between 2008 and 2014 among Japanese university freshmen. The results may be interpreted in several ways. First, there are some concerns related to the attitudes and behaviors of participants regarding IPV. For example, participants may not have reported real incidences of IPV perpetration because of an increased awareness that harassment is unacceptable through both formal and informal education. As a result, this study demonstrated no association between participation in IPV educational programs and perpetration scores. Previous studies also indicated that there was no association between IPV knowledge and the perpetration of violence ${ }^{6}$, 13). Educational programs could contribute to the promotion of awareness regarding harassment, but people may not report their own inappropriate behaviors (e.g., harassment) due to the recognition that such behavior is socially unacceptable. On the other hand, the perception of perpetration may be decreased among youths regardless of their participation in educational programs. Therefore, the participants in this study may not have accurately reported their experiences despite having perpetrated IPV. Another possible explanation is that young Japanese people, such as university students, may not have engaged in intimate relationships with members of the opposite gender. It is possible that such individuals had harassed non-intimate partners (e.g., friends, classmates, and/or others) before forming intimate relationships. These situations were not detected because data collection was performed in the first academic year, and most study participants had been high school students until a few months prior to data collection. Therefore, there is a risk of underreporting. This is reflected by The Gender
Equality Bureau Cabinet Office's reports about increases in some types of violence in the Japanese population ${ }^{4,5)}$. Several studies have also indicated discrepancies in the reporting and underreporting of perpetration and being a victim of violence and abuse $\mathrm{s}^{14-16)}$.

There was no significant difference in perpetration scores between male and female participants in this study, and perpetration scores were significantly reduced among male study participants between 2008 and 2014. It is necessary to consider gender and sexual orientation in IPV studies, which were not examined in this study as only heterosexual IPV was addressed. There is also the possibility of reciprocal IPV and interactions that involve an individual both perpetrating and being a victim of violence ${ }^{17}$. Further study is required to evaluate the detailed mechanisms and current trends regarding IPV among the younger Japanese population.

Determining the factors related to the perpetration of harassment will require not only emphasizing formal and informal education about IPV, but also addressing socio-familial background, including school-life conditions ${ }^{18,}{ }^{19)}$. Several studies have indicated associations between neighborhood conditions and the tendency to commit violence ${ }^{20,21}$. We suspect that there are higher rates of IPV among people with less supportive and preventive conditions, such as those involving inter-parental violence during childhood, a personal history of victimization, and poor mental health conditions ${ }^{22-24}$. However, this study found that the number of respondents reporting violent episodes decreased between 2008 and 2014. Although the results of the present study alone cannot be used to propose measures for preventing IPV, it will be crucial to focus on the actual number of reports, and to take the complexity and seriousness of the problem into consideration for the study results to facilitate the promotion of a healthy society. This includes the promotion of community solidarity, school cohesion, family connection, and individual well-being ${ }^{24,25}$.

This study does not present causal factors related to the perpetration of IPV, and the study sample is not representa- 
tive of the general Japanese youth population. Although the same questionnaire was used to compare results between 2008 and 2014, it was not an established tool for the assessment of dating violence, and was not verified for validity and reliability. In addition, the Cronbach's alpha in 2014 was smaller than that of 2008, and the questionnaire could therefore not appropriately reflect the contemporary conditions of the attitudes and behaviors of university students as related to dating violence. However, our results indicated a reduction in self-reported IPV instances from 2008 to 2014 among Japanese university freshmen. Further study is needed to identify the factors associated with IPV mitigation within the Japanese youth population.

Conflict of interest: The authors have no conflicts of interest to declare.

\section{Acknowledgements}

The authors are grateful to all involved students for their participation in this study, and also thank Nagasaki University.

This study was supported by Nagasaki University. However, the contents of this study are the sole responsibility of the authors, and do not represent the official views of Nagasaki University.

\section{References}

1. World Health Organization. WHO multi-country study on women's health and domestic violence against women. Geneva: WHO; 2005.

2. Black MC. Intimate partner violence and adverse health consequences: implications for clinicians. Am J Lifestyle Med 2011; 5: 428-439. [CrossRef]

3. Garcia-Moreno C, Jansen HA, Ellsberg M, et al. WHO Multicountry Study on Womens Health and Domestic Violence against Women Study Team. Prevalence of intimate partner violence: findings from the WHO multi-country study on womens health and domestic violence. Lancet 2006; 368: 12601269. [Medline] [CrossRef]

4. Gender Equality Bureau Cabinet Office. Assessment of intimate partner violence in 2014. http://www.gender.go.jp/policy/no_violence/e-vaw/chousa/pdf/h26danjokan-gaiyo.pdf (Accessed 28 January 2017).

5. Gender Equality Bureau Cabinet Office. Assessment of intimate partner violence in 2011. http:/www.gender.go.jp/policy/no_violence/e-vaw/chousa/pdf/h23danjokan-gaiyo.pdf (Accessed 28 January 2017).

6. Ohnishi M, Nakao R, Shibayama S, et al. Knowledge, experience, and potential risks of dating violence among Japanese university students: a cross-sectional study. BMC Public Health 2011; 11: 339. [Medline] [CrossRef]
7. Amemiya A, Fujiwara T. Association between maternal intimate partner violence victimization during pregnancy and maternal abusive behavior towards infants at 4 months of age in Japan. Child Abuse Negl 2016; 55: 32-39. [Medline] [CrossRef]

8. Kamimura A, Nourian MM, Assasnik N, et al. Intimate partner violence-related experiences and mental health among college students in Japan, Singapore, South Korea and Taiwan. Int J Soc Psychiatry 2016; 62: 262-270. [Medline] [CrossRef]

9. Kita S, Haruna M, Matsuzaki M, et al. Associations between intimate partner violence (IPV) during pregnancy, mother-toinfant bonding failure, and postnatal depressive symptoms. Arch Women Ment Health 2016; 19: 623-634. [Medline] [CrossRef]

10. Lundgren R, Amin A. Addressing intimate partner violence and sexual violence among adolescents: emerging evidence of effectiveness. J Adolesc Health 2015; 56(Suppl): S42-S50. [Medline] [CrossRef]

11. Spangaro J, Zwi AB, Poulos R. The elusive search for definitive evidence on routine screening for intimate partner violence. Trauma Violence Abuse 2009; 10: 55-68. [Medline] [CrossRef]

12. Shorey RC, Cohen JR, Lu Y, et al. Age of onset for physical and sexual teen dating violence perpetration: A longitudinal investigation. Prev Med 2017; 105: 275-279. [Medline] [CrossRef]

13. Borowsky IW, Ireland M, Resnick MD. Violence risk and protective factors among youth held back in school. Ambul Pediatr 2002; 2: 475-484. [Medline] [CrossRef]

14. Hetling A, Saunders C, Born CE. Missing domestic violence victims in welfare caseloads: the discrepancy between administrative and survey disclosure rates. J Health Soc Policy 2006; 22: 79-95. [Medline] [CrossRef]

15. Zimmerman GM. The covariates of parent and youth reporting differences on youth secondary exposure to community violence. J Youth Adolesc 2014; 43: 1576-1593. [Medline] [CrossRef]

16. Wenger MR. Patterns of misreporting intimate partner violence using matched pairs. Violence Vict 2015; 30: 179-193. [Medline] [CrossRef]

17. Fernández-Fuertes AA, Fuertes A. Physical and psychological aggression in dating relationships of Spanish adolescents: motives and consequences. Child Abuse Negl 2010; 34 : 183 191. [Medline] [CrossRef]

18. Reyes HLM, Foshee VA, Chen MS, et al. Patterns of dating violence victimization and perpetration among Latino youth. J Youth Adolesc 2017; 46: 1727-1742; [Epub ahead of print] [CrossRef]. [Medline]

19. Reidy DE, Kearns MC, Houry D, et al. Dating violence and injury among youth exposed to violence. Pediatrics 2016; 137: e20152627. [Medline] [CrossRef]

20. Reed E, Silverman JG, Raj A, et al. Male perpetration of teen dating violence: associations with neighborhood violence involvement, gender attitudes, and perceived peer and neigh- 
borhood norms. J Urban Health 2011; 88: 226-239. [Medline] [CrossRef]

21. Johnson RM, Parker EM, Rinehart J, et al. Neighborhood factors and dating violence among youth: a systematic review. Am J Prev Med 2015; 49: 458-466. [Medline] [CrossRef]

22. Fleming PJ. McCleary-Sills J, Morton M, et al. Risk factors for mens lifetime perpetration of physical violence against intimate partners: results from the international men and gender equality survey (IMAGES) in eight countries. PLoS ONE 2015; 10: e0126676. [Medline] [CrossRef]

23. Jewkes R, Fulu E, Roselli T, et al. UN Multi-country Crosssectional Study on Men and Violence research team. Preva- lence of and factors associated with non-partner rape perpetration: findings from the UN Multi-country Cross-sectional Study on Men and Violence in Asia and the Pacific. Lancet Glob Health 2013; 1: e208-e218. [Medline] [CrossRef]

24. World Health Organization. Preventing intimate partner and sexual violence against women: taking action and generating evidence. Geneva: WHO, 2010.

25. Dworkin SL, Treves-Kagan S, Lippman SA. Gender-transformative interventions to reduce HIV risks and violence with heterosexually-active men: a review of the global evidence. AIDS Behav 2013; 17: 2845-2863. [Medline] [CrossRef] 